\title{
Opening doors: A thematic analysis of the long-term impact of community-based research in the field of HIV
}

\author{
Vera Caine ${ }^{1}$, Judy Mill ${ }^{* 1}$, Jean Chaw-Kant ${ }^{1}$, Maggie McGinn ${ }^{2}$, Ray Chorney ${ }^{3}$ \\ ${ }^{1}$ Faculty of Nursing, University of Alberta, Edmonton, Alberta, Canada \\ ${ }^{2}$ Alberta Health Services, Edmonton, Alberta, Canada \\ ${ }^{3}$ HIV Edmonton, Edmonton, Alberta, Canada
}

Received: April 26, 2018

DOI: 10.5430/jnep.v9n2p85
Accepted: September 27, $2018 \quad$ Online Published: October 19, 2018

URL: https://doi.org/10.5430/jnep.v9n2p85

\begin{abstract}
Health professionals, including nurses, have been identified as a source of stigma for persons living with HIV (PLWH). Stigma towards PLWH may be predicated on the lack of basic education about HIV in pre-licensure nursing curricular, few opportunities for continuing education in HIV, and persistent discriminatory attitudes about HIV among nurses. From 2011 to 2013, in collaboration with the Canadian Association for Nurses in AIDS Care (CANAC), we developed and implemented a community-based intervention research project entitled A clinical mentorship model for Canadian nurses in HIV care. In previous publications, we reflected on the process, strengths and challenges of conducting this community-based research (CBR) study and we documented the improved knowledge, attitudes, and practices of nurses. Five years after the completion of our CBR study, we re-engaged with some of the participants, with the purpose of assessing whether outcomes had been sustained. We interviewed 15 of the original 56 participants. The data analysis was carried out using thematic analysis. In the current paper we highlight the themes of project design, in particular the CBR design, capacity building and relationships that emerged in our follow-up study. Overall participants looked back on their involvement in the mentorship project as a very positive experience that had opened new, unexpected doors. The participants described many areas of personal and professional growth as a result of their participation. Despite a period of more than five years since the completion of the initial CBR study, the community-based participatory design, the inclusion of PLWH as mentors, and the focus on experiential learning, were seen as fundamental to sustaining the long-term positive impact.
\end{abstract}

Key Words: Mentorship, Long- term, Impact, Nursing, Education, Community-based, HIV, Care

\section{INTRODUCTION}

More than 25 years after the first cases of Acquired Immune Deficiency Syndrome (AIDS) were identified, the negative health and social impact caused by stigma and discrimination towards persons living with Human Immunodeficiency Virus
(HIV) continues. Health professionals, including nurses, have been identified as a source of stigma for persons living with HIV (PLWH). ${ }^{[1]}$ Stigma among nurses may be predicated on inadequate basic education. Currently few opportunities for continuing education exist for nurses who

\footnotetext{
* Correspondence: Judy Mill; Email: judy.mill@ualberta.ca; Address: Faculty of Nursing, Level 3, Edmonton Clinic Health Academy, $11405-87$ Avenue, University of Alberta, Edmonton, Alberta, Canada.
} 
encounter PLWH in their practice, and few opportunities within the healthcare profession exist that will challenge discriminatory attitudes about HIV and AIDS. ${ }^{2]}$

From 2011 to 2013, we developed and implemented an intervention research project entitled A clinical mentorship model for Canadian nurses in HIV care, funded by the Canadian Institutes of Health Research. Recognizing the shift in adult education to lifelong learning, we considered non-traditional ways of helping nurses' acquire or improve their HIV patient care by providing supportive and collegial learning opportunities through a mentorship intervention. Employing a community-based research (CBR) approach, our mentorship intervention was based on mentoring and adult learning theory, particularly transformative education. ${ }^{[3]}$ A transformative educational approach facilitates a deep seated process to disrupt current experiences and perceptions with the goal to transform one's worldview. ${ }^{[3]}$ According to Grossman, ${ }^{[4]}$ mentoring as it relates to nursing specifically "encompasses a guided, reciprocal, formal or informal, evaluated experience ... over a period of time that empowers the mentor and mentee to develop personally and professionally within the auspices of a caring, collaborative, and respectful environment" ( $p$ 27). Furthermore, a wider appreciation of mentoring relates to how we can use it to secure change in practice, pursue additional learning opportunities, increase self-confidence and achieve career goals. ${ }^{[5]}$

Community-based research has the potential to contribute to capacity building and community development ${ }^{[6-8]}$ and benefits both the research endeavor and the stakeholders involved. ${ }^{[9]}$ Fundamental principles of CBR include: the involvement of community members in all stages of the research process to ensure that it is relevant and applicable to people's lives; the valuing of local knowledge and experience; the empowerment of participants to contribute to lasting change; and the development of the skills and abilities of all partners to maximize resources. ${ }^{[6]}$ Focusing on the impacts of CBR helps us to highlight the somewhat often overlooked issues of engagement research ${ }^{[10]}$ and the need to document impact and engagement at the community level. ${ }^{[11]}$ Another principle of CBR is to ensure participants are able to contribute to social improvement that goes beyond the research project's life, and hence contribute to lasting change ${ }^{[6]}$ however, the connection between CBR and broad community results is lacking. ${ }^{[10]}$

In our previous study, we contributed to knowledge about best practices to improve the quality of life for PLWH and developed an in-depth understanding of best practices when providing mentoring opportunities for nurses. We reflected on the process, strengths and challenges of conducting a large CBR study ${ }^{[12]}$ and we documented the improved nurses' knowledge, attitude and practices after participating in a CBR nursing intervention in HIV care. ${ }^{[13]}$ The need for time and space for critical reflection for nurses (mentors and mentees) and the inclusion of PLWH mentors were considered essential for learning uptake. ${ }^{[13]}$ We also affirmed that having both a nurse and PLWH mentor was perceived by all of the nurse participants as invaluable, and honored the Greater Involvement and Meaningful Engagement of People living with AIDS (GIPA/MEPA) and people at risk. ${ }^{[14]}$ The purpose of the follow up study was to systematically inquire into the long-term impact of conducting community-based intervention research in HIV care.

Five years after the completion of regular informal meetings and the last formal workshops at each site that were part of the design of the initial project, we became aware of numerous unintended positive consequences that are significant. For example, former participants mentioned that: some of the nurses had begun graduate programs with a focus on HIV; there was ongoing collaboration between acute care and community-based clinical sites and community agencies, including AIDS Service Organizations (ASOs); and there was a continuing mentoring relationship between nurses involved in HIV care. This unsolicited, anecdotal evidence gathered through email correspondence, telephone calls, and informal discussions led us to develop a follow up study to investigate the long-term impact of our CBR project. The purpose of the follow up study was to systematically inquire into the longterm impact of conducting community-based intervention research in HIV care. This research is particularly important because knowledge translation researchers suggest that traditional continuing education (such as didactic learning) and dissemination approaches (such as textbooks) have little impact on clinical behavior. ${ }^{[15]}$ In addition, mentorship and training are critical factors to cope with the rapid scale-up of high quality services needed in acute, long-term care and community settings. ${ }^{[16]}$

\section{DESIGN, METHODS AND RESEARCH RE- SOURCES}

After receiving ethical approval from the University of Alberta Health Research Board, semi structured interviews were conducted with individuals who had participated in the previous research. Two research assistants and one member of the core research team conducted the interviews. Each interview was between 30 to 45 minutes in length. Written informed consent was obtained from all participants. Purposive sampling was used to recruit participants, who were then contacted through the relationships already established with the primary researchers or AIDS Service Organizations 
and clinical practice sites. Purposive sampling was chosen to ensure heterogeneity. Guiding questions related to the impact and experience of participating in a community-based mentorship project were used to explore the long-term outcomes and make visible the processes through which these outcomes were achieved. Interviews were transcribed verbatim, and anonymized.

The data analysis was carried out using thematic analysis in order to identify common themes and patterns. ${ }^{[17]}$ Thematic analysis relies on processes of constant comparison to develop insights into human experiences. After reading the transcripts the authors met to develop an initial coding framework. This framework was modified and revised as we gained new insights about the data and relationships between the major themes. We used NVIVO 11 qualitative software $^{[18]}$ to assist with the labeling, revising and the retrieval of codes and writing memos. Morse's ${ }^{[19]}$ taxonomy, including comprehending, synthesizing, theorizing, and the re-contextualizing data was used to guide the inductive and iterative content analysis. In order to increase study design rigor, we emphasized keeping the goals of the research in mind and contributing in ways that speak to a) what can be learned about the phenomenon and b) how does this knowledge shape practice. We were most interested in linking our CBR project with potential impacts in HIV care "that outlast the specific research endeavor and contribute to community improvement down the road". [11]

As part of the current research, we worked with two PLWH, one of whom is a Registered Nurse and one who works with an AIDS Service Organization (ASO) and served on the advisory committee for the duration of the initial mentorship project. These PLWH engaged in the data analysis and manuscript writing phases of the study. Involving PLWH in all aspects of the work is consistent with the GIPA/MEPA and CBR. ${ }^{[20]}$

\section{Findings}

We conducted a total of 15 interviews with individuals who were participants in the original mentorship study: 5 nurse mentors; 4 PLWH mentors; and 6 nurse mentees. Three of the participants were male and 14 were female. Nine of the participants had participated at urban mentorship sites and 6 had participated at rural sites. In addition, we interviewed one collaborator from an ASO and one representative from the Canadian Association of Nurses in AIDS Care (CANAC), who provided confirmation of the identified themes.

Overall participants looked back on their involvement in the mentorship project as a very positive experience that had often opened new, unexpected doors. For example, one of the

Published by Sciedu Press
PLWH mentors believed that her involvement had enriched her relationship with community members. She shared that the mentorship project had:

Opened so many doors for me, and it actually opened some people's eyes that worked with me in other communities... they had never thought that we could be in that position [PLWH mentoring nurses], so it really actually opened up a whole slew of doors for me. That put me almost on an equal plane, like I actually had something to say. (Rural PLWH mentor)

Another PLWH mentor who had participated in the mentorship project at multiple sites also believed that the project had opened doors and provided new networks for him:

Well, it's opened doors to just meeting others, people that are involved in HIV, and so going to these different communities, like [urban site] and [rural site], yeah, once the door was open, it was just, like, wow, my networking just expanded up to, like-oh, just unbelievably. (Urban PLWH mentor)

The participants in the follow up study described many areas of personal and professional growth as a result of their participation in the mentorship project. Many of these themes confirmed those described immediately following the initial mentorship project. ${ }^{[2,12,13]}$ In this paper, we have chosen to highlight findings that demonstrate the longer term impact of participation on the nurse and PLWH mentors and the nurse mentees. These findings are organized in themes related to the project design, capacity building and relationships following the project.

\subsection{Project design}

Despite a period of more than five years since the completion of the initial study, the community-based participatory design, inclusion of PLWH, experiential learning, and location of meetings, were consistently mentioned by participants as fundamental to the long-term impact of the mentorship project. The community-based, participatory nature of the design was seen as critical to the success of the mentorship project by helping to enhance the long-term impact. One of the urban nurse mentees provided a very compelling summary of the impact of her involvement. The positive impact on her personal self was entwined with the community-based approach that was utilized:

So I don't think at the time, I had a strong enough appreciation for the project. But looking 
back now, I do; I appreciate it a lot more, and I understand more of what it has given me. So I'm hoping that it gives more to the research world and it proved its point that these types of community settings are beneficial to people, especially the involvement with both academics, people working in the field, as well as people living with HIV. So I think having all of those aspects come together is really, really beneficial. So I definitely appreciate the project more and more now. (Urban nurse mentee)

A nurse mentee from another urban site who worked in acute care attributed the mentorship project to deepening her connections with the community:

And I think that in acute care, we're so bubbled. And we see it all the time where we're sort of in this bubble: they come, they're really, really sick, we fix, and then we send them on their way, but there's no-we don't know what happens. We don't know if they've gotten better, we don't know if there maybe other comorbidities, like addictions, that have gotten worse. Like, if they don't come back, we don't know if it's a good thing or a bad thing that they don't come back. So it's nice to be able to see the community and see, oh, yeah, there's tons of people out there that are doing fine. (Urban nurse mentee)

The authentic engagement of participants and flexibility of design are core principles of CBR. During the mentorship project we attempted to be responsive to the learning needs of the participants, both nurses and PLWH, to ensure that they were meaningfully engaged. For example, a rural nurse mentor appreciated the flexibility to tailor the content of the mentorship group meetings to meet the learning needs of the nurse mentees:

I made it very much about their learning, and they would give me topics, for example that they wanted to know more about for the next meeting, and so on. Because I didn't want it to look or appear like it was my agenda, because then you lose the masses; you want to tailor-make it to them and their needs, and so that's what I attempted to do anyways. (Rural nurse mentor)

Another rural nurse mentor commented on the advantage of allowing the mentorship meetings to respond to the learning needs of the group, rather than being instructor driven: 88
I don't know if that's the way it was supposed to be initially, or that's just the way the group steered it in different ways, which I think was good. I mean, you can look up what you need to do when a patient is started on medications; you can't look up in a book different things that we learned going through the journey. (Rural nurse mentor)

Interestingly, but not surprising to us, the involvement of persons living with HIV was viewed as fundamental to the success of the project. A nurse mentee at one of the rural sites believed that:

The peers $[\mathrm{PLWH}]$ being part of the team is the biggest highlight, and [I] actually recognize them to be part of the solution - not to be studied upon, but to be part of the solution of finding the answers. And that's been a part of the lived experience for me, and I continue to advocate for that because it is through their eyes that we have to improve our care and how we deliver services to them. (Rural nurse mentee)

An urban nurse mentee also emphasized the importance of including PLWH in the project design. When asked what the most meaningful aspect of the mentorship project was she commented:

To be partnered up with folks who are living with HIV, I think that that's really important, because we can only empathize, we don't actually know truly what it's like to live in those shoes and to live with those experiences... So there's just a lot of stories out there, but it was really neat and powerful to hear that firsthand. So that was really great that they could share that with us. It just rounded out the understanding from patient-person experiences living with HIV, rather than having a flattened understanding or a less-deep understanding of a client-patient experience... (Urban nurse mentee)

One of the urban nurse mentors, although experienced in HIV care, shared that she often did not have enough time to hear the life stories of her patients. She found that visiting agencies serving PLWH and having them integrated into the project were valuable aspects of the design:

I think the perspective of the peer navigators and different agencies that we went to, like [Indigenous ASO], and spending time with people 
who, for example, are affected by HIV on a daily basis. Because we often don't have that much time to spend with people that we work with - with the patients, so I found that really valuable. (Urban nurse mentor)

The deliberate inclusion of experiential learning opportunities, such as story-telling and body-mapping, were design features that contributed to the positive long- term impact of participation. When asked what the most meaningful aspect of the mentorship project was, an urban nurse mentor replied "I would say probably the experiential portion of things stand out to me the most. Not new information" (Urban nurse mentee). One of the nurse mentees in an urban setting had really appreciated hearing the stories that the PLWH shared in the mentorship groups:

....it's the personal stories people really care about, isn't it, 'cause it puts a face to your patients and gives you a better understanding of what they're going through. (Urban nurse mentee)

Similarly, a nurse mentor felt that hearing the stories of the PLWH was a highlight of the project:

Just the sharing of ideas, especially from the people that were there from [local ASO] and sharing of their-I think we had a speaker that shared his story about living with HIV/AIDS. I'm someone who's very collaborative, so I liked the team approach that the meetings had, the openness of the meetings, and the focus on communication. (Urban nurse mentor)

A number of the participants commented on the powerful experience of participating in body mapping (this is a form of visual self-representation). One of the rural PLWH believed that body mapping had helped to reduce the power differential between herself and the nurses and was a highlight of the project:

[The thing] I really, really appreciated was that body mapping. When we did that body mapping, we were all on the same page. I'm not the PLWH and you're not the nurse or you're not the head of this... So I really enjoyed body mapping. I still love it today, because I think it gives us common place, common ground. And we're on the ground, as Mother Earth, which is really cool. (Rural PLWH mentor)
An urban PLWH mentor had previously learned about body mapping through the ASO that he volunteered with. He found body mapping very helpful to learn how HIV had affected his body and was very happy to participate in it again as part of the mentorship project:

Once I did that body map, then that opened my eyes to HIV and how it affects my body. Yeah, that opened the door, and when I walked through, then I saw all these people, and I thought, "This is great." (Urban PLWH mentor)

An urban nurse mentee believed that body mapping was a powerful experiential learning strategy:

The body mapping piece really stands out for me because there's a felt sense of the experience which is very different than having somebody talk-talk-talk, which is also important, but to actually have that... (Urban nurse mentee)

Similarly, the CANAC representative remarked on the powerful outcomes associated with integrating experiential learning into the design:

That kind of experiential or interactive learning always seems so much more relevant than just didactic kind of lecturing or giving of information. Obviously, doing the body mapping maybe has people thinking about things they wouldn't think about, and more empathy for patients, because they're even looking at themselves when they did it, and bringing that touch back that these are real people and this is what's happening to them, and that kind of thing. (CANAC representative)

Prior to the implementation of the initial mentorship project, the research team strategically chose the location of the mentorship meetings to maximize opportunities for the development of authentic engagement and sustainable partnerships. An urban nurse mentee recalled:

...we are in the space of that organization [ASO] that helps support people with HIV, and you get to hang out in that space, so it becomes something that you are physically familiar with, and then you feel like you have a little more of an idea of what they do and you can really wholeheartedly recommend that as a resource to people who are struggling just to get their heads around "What does this mean for me now, this new diagnosis, new way of being?"... So that was really good. (Urban nurse mentee) 
At another urban site, one of the nurse mentees found it very helpful to have the mentorship meetings in a community agency. She recalled:

I'd never been to [community agency] before, and just to be able to see the visual of the layout and how things worked there was really helpful... I think just knowing about [community agency] and knowing what they did, and then actually just seeing how the patient flow and everything worked and what the space looked like... (Urban nurse mentee)

At one of the rural sites, most of the mentorship meetings were held in the public health office in the small town. On one occasion, the mentorship group travelled outside of the town and held their one day meeting on the nearby reserve. This was one of the most powerful and memorable experiences for the PLWH mentor:

I think it was definitely being off-site. I remember going into the community of [name of reserve] and just feeling-I think as we were going through the project, we all became very close, and just being in a spiritual place, I think, would just even bring us more together. So I think it was just practicing traditions and just exploring ourselves and why we think the way we do, and learning more insight and having a better appreciation of others as well, especially with barriers that patients who are living-or mentors living with HIV experience on a daily basis. Healthcare providers, we don't always think that way, and I think that was the biggest thing coming out of the project was that we have so much to learn from patients who are actually walking the journey with HIV. (Rural PLWH mentor)

\subsection{Capacity building}

Both the nurses and the PLWH reflected on their increased capacity and confidence following participation in the project. This change, in turn, enabled the PLWH to become more meaningfully and authentically engaged with issues related to HIV and AIDS. One of the nurse mentors had helped to recruit two PLWH at the rural site that she worked with. The nurse was extremely pleased that a previously introverted PLWH had gained confidence and began to engage with the community following her involvement in the mentorship project:

This is a PLWH who hung her head low, and I think that it is definitely thanks to the mentor- ship program, she saw that there was a bunch of nurses around the table who didn't judge her or treat her any differently, and I think she needed that constant exposure to healthcare to see that - and then she gained a certain comfort to a point ... she took part in a patient panel in her own city where she put herself in front of a crowd of her home town and sat there and told her story that she was HIV-positive. I was so proud of her. (Rural nurse mentor)

The collaborator from the ASO had also observed increased confidence among PLWH who had participated in the project:

We have a [client] that has been quite ill for a couple of weeks for different reasons and one of the participants from the mentorship program has been taking him to the hospital and going in the taxi and making sure he gets home... And I think it's because of the mentorship and giving that empowerment and making those connections [with hospital nurses] that they feel comfortable to do that. (Urban collaborator)

The inclusion of Indigenous participants in the project design was also critical to establish the trust necessary for authentic engagement. One of the Indigenous PLWH commented on this approach:

I really appreciated that these were First Nations nurses, people of colour. I know it wasn't all the white colonized European settlers that were with us; these were my peers, these were my people. To have that was really amazing. (Rural PLWH mentor)

All of the PLWH that we interviewed spoke about the positive impact of their participation. Interestingly, one of the PLWH commented not only about the positive impact of the project on herself, but also on other PLWH:

It totally had an impact. And other positive people too; they were, like... they shunned me first [then they] come back, then okay, it's okay. (Rural PLWH mentor)

An Indigenous PLWH mentor had become involved with both provincial and national organizations following the project:

And then I also now volunteer being a board member to [provincial Indigenous ASO organization] —it's an HIV organization — and then nationally with [national Indigenous ASO]. So 
yeah, that, I would say, would be a stepping stone, to always ask the question, "How can I improve?" And it is through the voices and the experience, the lived experience to advocate for our clients. (Rural PLWH mentor)

This participant, as an Indigenous person living with HIV, was committed "... to improving the services in my community, and advocating, and so... we have our own [Indigenous] HIV strategy".

Several of the nurse participants credited their participation in the mentorship project with the motivation to pursue further studies and certifications, thereby increasing their capacity to provide evidenced-based HIV care. For example, one of the urban nurse mentees thought that her participation in the project had provided the incentive to pursue her Master's degree:

Doing that thesis work, I think that's where the outcomes come through... we talked about Point of Care testing during the mentorship program, and then I had done it through my work, professionally, and then being able to bring that through into my thesis. So the outcomes kind of became outcomes of another research project. (Urban nurse mentee)

Following the project, a rural nurse mentee had pursued additional HIV certification and a career in HIV nursing care:

I eventually became the HIV nurse clinician for our health region and went and took my ACRN certification. So it opened up a whole bunch of doors and just piqued my interest even more and my interest to learn more. (Rural nurse mentee)

Nurse mentors and mentees described enhanced capacity to advocate including: the ability to engage in policy and program development; an ongoing commitment to HIV care; and increased involvement in organizations dedicated to HIV prevention, care and support, as a result of participation. An urban nurse mentor felt that her involvement in the project had enhanced her ability to shape policy:

Maybe influencing policy, cause we regularly meet here to discuss our programming, and I know there have been some-I mean, the navigator program, I don't know if it came out of this, but it was developed, and Stop Outreach programs [to provide short term intensive case management in the community]. Not being particularly involved in them, but being aware of the programs that are out there and the services. (Urban nurse mentor)

When asked what outcomes had the most impact, one of the rural nurse mentors felt that having more knowledge about HIV meant that nurses were better able to advocate for patients:

So the advocacy piece for sure. I would like to think a better outcome for patient care; again-I'm sorry, I don't mean to sound like a broken record, but to me, that's all part and parcel. I mean, if you have better knowledge, whether that knowledge is [call one of nurse mentors] and you don't know anything else, at least you know who to call, and the outcomes then would become different, potentially, for that patient. (Rural nurse mentor)

A nurse mentor from a rural community commented that some of the nurse mentees had independently developed new programs as a result of their participation:

We have people that were involved in the project are definitely self-sufficient now, and they've developed their own way of doing things and developed amazing programs in their home community, which was absolutely important. And it really wasn't the nurse mentors that-I don't think we had a lot to do with that (Rural nurse mentor)

This mentor linked increased self confidence among the mentees to improved patient care:

So patients now, instead of having to come into the city and possibly be subjected to other triggers or barriers just getting here, they are now being treated and cared for in their own communities from nurses that have been mentored by nurses that were involved in the project. (Rural nurse mentee)

A nurse mentee from the same community reiterated that her involvement in the research project helped to bring about program changes:

I think any time you do research, it's a vehicle of effecting change, so with our experience particularly, it has affected-in our community, it has enhanced programming. So we were able to establish stronger linkages with setting up a community outreach infectious disease clinics. (Rural nurse mentee) 
In addition to increased capacity to engage in advocacy activities, nurse mentors and mentees alike described meaningful aspects of the mentorship project that had increased their capacity to provide respectful and evidenced based care to PLWH. As one of the rural nurse mentors stated, "Ultimately I think that it led to better patient care because they knew who to call" (Rural nurse mentor). A nurse mentor at another rural site believed that her ability to provide culturally safe care, particularly to Indigenous patients, had been enhanced through her participation in the project. She recalled:

I had always thought that I was pretty knowledgeable into First Nations culture, but since found out I didn't really know what I needed to know when we talk about cultural safety because I'd always thought I was fairly knowledgeable, but not after this. I learned so much. Which was another key aspect of the study, and that it all just comes down to respect of one another and respect of each other's cultures and beliefs and traditions. We were very respectful on both sides, whenever we-you know, we discussed lots of traditions and different backgrounds. (Rural nurse mentor)

This nurse mentor also believed that "... knowledge that you gained... especially from the mentors living with HIV" had increased her skill in providing culturally safe, respectful care. One of the rural nurse mentees who worked in corrections felt that her participation in the mentorship project had helped her to take a more holistic approach with her HIV positive patients. She shared:

We managed to put together-rather than just having a nurse and a doctor taking the role of healthcare providers, we ended up putting together a whole team of healthcare providers, which included outreach support, a social worker, and involving lots of different outside agencies, again, just to try and meet the urgent needs of the client. Because as I said, we sometimes found that the client may be HIV-positive, but that's really not on the top of their priority list, nor is it what needs to be looked at right this moment. (Rural nurse mentee)

A rural nurse mentor believed she had become more patient centered in her nursing practice due to the involvement of PLWH in the mentorship project:

Again, we learned the most from them [PLWH], and to be able to hear their perspective on what their journey and what the bumps in the road look like for them was definitely an eye-opener. And certainly from my point of view is it really did change the way I nursed following that. A little bit less focus on clinical data and medications_- "This is all we need to do"- - and to not put that first, but to put patients first, and the other stuff will come. (Rural nurse mentor)

Several of the nurse participants credited participation in the mentorship project with helping to develop their confidence and leadership capacity. An urban nurse mentee commented that "... the knowledge [from the project] has given me a little bit more confidence for understanding the impacts of what this infection brings to the lives of those who experience it and the people that love them". (Urban nurse mentee)

A rural nurse mentee remarked that the mentorship project had provided her

... with the leadership in managing our health programming. As well, enhancing the programming. As well, research-more research opportunities, taking part in research and co-authoring and ... we were featured with [name of community] one of the communities that were showcased in [a provincial HIV program]. So our community was part of that. I do a lot of presentations as well, conference presentations. (Rural nurse mentee)

When asked if the mentorship program had helped to develop her leadership abilities, an urban nurse mentor replied that "it provided me with some guidance, some answers I may have been seeking, extending my active listening skills. Also my presentation skills: speaking in front of others, public speaking" (Urban nurse mentor)

The CANAC representative believed that the mentorship project had increased nurses' capacity by providing opportunities for those more experienced in HIV care to mentor those with less experience:

What I remember most about the project was always feeling like this was an important thing, that we look at how we could mentor other people in this field, because there is so many of us that were in the field for such a long time, and knowing that we won't all be here forever and that more people need to be involved, and there's more. (CANAC representative). 


\subsection{Relationships}

Participants also described the opportunities to establish new relationships and networks, and sustain existing ones, as a result of their participation. An urban nurse mentor commented that:

The networking was great, learning new ways of learning and getting to know the different people, working with the peer navigators-it was just such a great experience. [I developed relationships with] a couple of the peer navigators, a few nurses from other areas in the hospital that I wouldn't usually have the opportunity of working with. And then it was really great to deepen relationships I'd already had with some people. (Urban nurse mentor)

A nurse mentor who worked in a smaller centre spoke about a new relationship that she had developed with the sexual assault program in her area:

They would not have known of me had it not been for [nurse mentee] who was part of the mentorship program. So I have since met with the director of the sexual assault program, who knows me by name, and so I think that they we actually shared our hospital policy for the [HIV] meds and so on with them. (Rural nurse mentor)

A collaborator from an ASO also confirmed the impact of the mentorship project on relationships. Following the mentorship project, the team of hospital-based professionals who provided care to PLWH began to meet at the ASO:

I think it's about building relationships. Because when [hospital based program] meets here, so all the dietitians, the nurses, the doctors, all of the support are here in the building twice a year, and they're interacting with our clients during the meeting.(ASO collaborator)

One of the most significant long-term outcomes was on the ability of participants to sustain relationships well past the mentorship intervention. At the time of the interviews for this project the interventions at all sites were completed at least 5 years previously. Many participants had chosen to stay in touch with us, through telephone calls, emails, or through visits to our offices. These connections were welcomed given our own long-term interest in the field of HIV.

Critical to the ability to sustain long-term relationships is the element of building trust. Through building trust, other objectives such as learning can be achieved. This trust is also marked by a strong sense of responsibility. As one rural PLWH mentor shared:

I do hold a lot of responsibility in speaking for other people, and I'm very honored to do that... And I hope I do it correctly. I always say to them, "If I'm doing something wrong, tell me". (Rural PLWH mentor)

Through their participation, some nurses and PLWH recognized that HIV care happens across multiple diverse physical sites and that it was important to focus on the goals of care, rather than the differences in where care was provided. This recognition fostered a sense of the importance of sustaining relationships across practice sites:

... just to make those community connections and to try and not be so siloed [isolated] in acute care... like, we're all working towards the same goal, so it's just, like...I don't think it's the same people-like, I'm not talking to the same people that were in the study, but I'm still talking to people that-we're all out there for the same goal. (Urban nurse mentee)

These sustained connections across practice sites where also important to PLWH. One of the rural nurse mentors indicated:

I think just by working together with our peer mentors who are living with HIV, I think that there was a trust that was developed, and we still, to this day, we'll get referrals right from our peer mentors...We're still in touch occasionally with our peers living with HIV, which is wonderful; again, they will bring patients in or they may just give us a call and say, "I just need some medical information. Where do I find this, because I need to pass this on to a friend." Those relationships are still there, not that we-those peers are not directly possibly living near us anymore, but just making that relationship and them knowing where they can reach out, I don't think that would have happened without being involved in the project. (Rural nurse mentor)

A PLWH mentor spoke about her ability to make referrals to nurses of other PLWH or people at risk for HIV. She shared that "I always will call them if I need something. ... I'm still very connected with these nurses" (Rural PLWH mentor).

For nurses working with Indigenous clients in rural communities and communities that provided care on First Nations 
reserves, it was critical to address structural barriers and challenges. Recognizing that their struggles were shared and that they could find solutions together helped sustain their long-term relationships.

So from our nursing colleagues: the participants, I think definitely just developing those relationships and trust between invisible jurisdictions, I guess. We were able to break down some of the barriers that might have existed between different health regions...we were able to talk freely about what some of the challenges were... I think, again, establishing the relationships and developing that trust between a clinical setting in a city versus nurses working frontline in their own community. I think by being part of the project, that was key as well. Because of those relationships that were built, we always knew that we had everyone's support. (Rural nurse mentor)

\subsubsection{The Ability to Make Referrals}

One of the key aspects of sustaining relationships well past the end of the initial intervention project was the ability to make referrals across different practice sites. There was a new appreciation of the needs of others who also provide care to PLWH. Two of the urban nurse mentees and a nurse mentor commented on their increased ability to make comprehensive referrals, particularly in relation to discharge:

I think mostly I'm super conscious of trying - and especially now, doing the job that I do now, being especially conscious of trying to inform community about discharge, making sure their follow-up plans are set up and that people that are going to facilitate patients are going to follow up and know about their appointments and that sort of thing. (Urban nurse mentee)

I think the past was we just discharged them as though these people in community would then get this person and then would have to fish through all online documents or discharge summary or whatever in order to figure out what was going on. It's so much easier to just have that personal, "I'm discharging them. Do you have any concerns? This is what our plans are for them; does that sound good for you?" Yeah. (Urban nurse mentee)

Yes, and I think in one sense is I learned so many new ways of...who to connect with or who to seek out if I need more information...because
I now know more people at different agencies. (Urban nurse mentor)

Given that many participants at the start of the intervention spoke about their lack of connections with other care providers at different practice sites or ASOs, the ability to make referrals across practice sites was a significant and positive change. It also became evident that it led to a greater recognition of what each care provider in these different practice sites was able to contribute to the care. In some cases this brought new awareness to practitioners about their own practices, as well as it allowed discussions about what shaped HIV practices, policies, and programs.

\subsubsection{Personal relationships}

For some of the participants the ability to connect with others who had a vested interested in HIV care, went beyond professional connections. Some connections were marked by a personal interest in each other's lives and well-being, as well as their personal growth. One of the PLWH mentors described the following experience:

... when I feel discouraged, these women [nurses that were part of the intervention] seem to be here. I was at my first Sundance, and I wasn't allowed to be in the Sundance, I wasn't allowed to camp around it, wasn't even allowed to use the washrooms because they were afraid of my HIV and this was 2 years ago-just 2 years ago. I felt so displaced. It was very hard... I felt so lonely there. And all of a sudden, [nurse mentee] popped up, and I just cried. She said, "Keep going. Do what you need to do." To have her there and know that I mentored her years ago, and to have her encouragement and just shove me back into the circle was really cool! She gave me a hug and she touched me. Just to have that. She knew what it was like 'cause I had talked to her years ago of how we don't get physical touch, we're not allowed in our ceremonies. Just to have that - she had that knowledge. So she changed that whole thing for me and I was able to Sundance just last year, and I will do it again, 'cause I know my place. (Rural PLWH mentor)

These personal connections rippled throughout the lives of several participants. Some attributed their ability to connect in this way to the way the intervention was designed. The design of the intervention had focused not only on gaining skills, but also on sharing meaningful and relevant lived experiences. At times these personal connections also helped 
propel participants' professional development. An urban nurse mentee believed that:

Well, there's a few that are lasting relationships. So with [co-Principal investigator], she ended up being my thesis supervisor for a master's program, so I will always have a relationship with her, for sure. As well, [co-Principal investigator] helped me get into the master's program. So those relationships have definitely impacted me, as well as some of the other participants I worked with already, so it actually did strengthen our working relationship. And then one of the mentors, her Mom was my friend before meeting her, and then we've had such a strong relationship since being part of that mentorship program that my son actually calls her mom "Grandma," and we talk weekly probably, share baby stuff, and babysit each other's kids. So yeah, definitely had some strong relationships come out of it.(Urban nurse mentee)

\subsubsection{Building new networks}

While many participants talked about their ongoing and sustained relationships with others who participated in the intervention, some also commented on the ripple-effect the project had in forming new mentorship relationships. A rural nurse mentor had observed the nurse mentees mentoring other nurses:

I would definitely do it again...it was a great way to connect and start building those relationships. And it definitely helped, because there are numerous projects being developed, and we still all talk pretty much on a regular basis. I think those roots have definitely spread, and those colleagues, they're their own mentors now to other nurses. I think the collaboration definitely improved care and knowledge. (Rural PLWH mentor)

As is visible in the above quote, the ongoing mentorship has impacted care and knowledge. This is important, particularly at a time when HIV care is integrated with care for other infections transmitted sexually or through blood. Therefore, HIV is no longer seen as an exceptional disease. One of the PLWH mentors commented that:

I probably [would do something like this again], although my consideration now is aging and retirement; I just want to move on. It has nothing to do with the fact that it's educational; I think it's great. I would like to see more young people involved in this type of thing so that we could start bringing up a group of people that are more attached to community and to research. (Urban PLWH mentor)

This sense of intergenerational community building is an important aspect of building and sustaining long-term relationships between PLWH, nurses, and organizations.

\section{Discussion}

Keeping in mind our intention to explore the long-term impact of CBR research in HIV, three interrelated themes emerged and included: project design, capacity building, and relationships. These themes, while explored separately, were intertwined. The initial mentorship project was strongly focused on capacity building and the development of relationships. Throughout the implementation of the intervention it became difficult to separate these elements and they often worked synergistically. The ability to focus on the design, capacity building, and relationships was important at the time of the project; ${ }^{[12,13]}$ this importance was reinforced through our current findings. At the time of the initial project we did not name specific educational outcomes, but were much more focused on unfolding processes at each of our research sites. This allowed us to implement interventions that were site specific and guided by local contexts, happenings, and capacities; as a result local learning became participant driven. We can see now how important this was to the long- term success of this project. Reflecting back to the time when we were engaged at all of our sites, we are reminded of the energy that was needed to attend to the relationships, capacities, and challenges that needed to be considered in order to engage all participants in meaningful ways.

Participants in our follow up study highlighted the significance of relationships. For us as researchers, we took great joy in the relationships we formed across all sites and it certainly remains one of the highlights for us in this project. We were very wakeful to the idea that in transformative learning, relationships between mentors and mentees are critical. ${ }^{[3]}$ Thinking about meaningful and respectful interventions that focus and sustain nurses' capacity, it is necessary to focus on building relationships across diverse practice sectors. While the relationship between nurses is significant, the relationships built with PLWH is equally important. Learning about people and also about how the community works is vital in HIV care. With a strong focus on relationships, perhaps we underlined the humanness and relational care that we have come to see as central to HIV care. It certainly called us to live with a sense of responsibility for others, responsibilities 
that extended far beyond the life of the project. What is noteworthy in the findings is that this sense of responsibility and care also extended to participants.

This sense of care also enabled us to establish safe and respectful spaces that made engagement of all participants possible. While we did not name particular educational outcomes, the advisory committee and research team of the initial project pointed out the importance of engaging in experiential learning activities. It was these activities, such as body mapping, or community visits, that participants still spoke of several years after the intervention was completed. Some participants also pointed out that the experiential activities had a significant personal impact and shaped their practice.

Key to the design was the involvement of community members in all phases of the research process. It was important to value local knowledge and the unique experiences each participant brought to the study. In addition to the participants it was also important to value the knowledge of others who came to be part of our work, such as local community stakeholders, experts in the field, Indigenous Elders, and other PLWH. They contributed knowledge, wisdom, and critical insights into cultural, social, legal, and structural issues in HIV care. These principles are critical to the success of community-based research. ${ }^{[6]}$ Local knowledge came in different forms; at times it came through those we invited to facilitate part of the learning, while at other times, it came through the participants themselves who worked in diverse practice sites. PLWH were members of the research team, advisory committees and were also mentors during the intervention. Commitment to the GIPA/MEPA principles places PLWH at the centre of our work, including knowledge dissemination efforts. GIPA/MEPA link to capacity building that remain critical in this area of study.

The findings from the current study contribute to our understanding of the long-term benefits of CBR, particularly related to capacity building. It has been argued ${ }^{[6]}$ that capacity building among research partners is a hallmark of ethical, rigorous research. To date research has focused on short term changes in the knowledge, attitudes and practices of interventions with nurses in HIV care; ${ }^{[21]}$ however, there is a paucity of research that examines the long-term capacity development of participants in community-based HIV research. Despite a long history of funding CBR, to our knowledge, no research exists that assesses the long-term impact of CBR in the field of HIV. Following up with over $25 \%$ of participants, 5 years after the intervention was completed, highlighted some of the long-term impacts of the project, as well as it highlighted some of the fundamental principles of CBR.
Participants, both nurses and PLWH alike, shared that they gained confidence and felt empowered following their participation in the study. Several participants commented that they did not become aware of this change until long after the completion of the project. As a result of their increased capacity, new doors opened for participants in education, practice and advocacy. Nurses became engaged in political advocacy while some of the PLWH commented that their participation, and the opportunity to mentor nurses, helped to increase the respect that they were given by their peers and communities.

\section{Limitations}

This study was a follow up study to a national CBR project. While our formal ethics application expired at the end of our initial study, many participants stayed in touch with us. For the current study our sample included primarily participants who had maintained contact with us or who we were able to contact readily. We did try to contact participants who had moved, retired, or no longer worked at their previous place of employment, but it was challenging to locate them. The participants for this study thus represent a very select group. One of the other limitations of our initial study, as well as this follow up study, was that although participants frequently spoke about improved HIV care as a result of their participation in the initial project, we did not actually observe care. In future research endeavors, it would be important to directly observe care practices of participants.

\section{Conclusion}

Despite a period of more than five years since the completion of the initial study, the CBR design, the inclusion of PLWH as mentors, and the focus on experiential learning, were seen as fundamental to sustaining the long-term positive impact that was achieved. This follow up study reinforced the importance of attending to the GIPA/MEPA principles in enhancing capacity in HIV care. In order to enhance capacity-building opportunities in HIV research and care, advancement in understanding the processes by which intervention outcomes are achieved need to be documented. Our research findings make significant contributions to the methodological advancement of CBR by providing insights into the long-term impact of an intervention research project.

\section{ACKNOWLEDGEMENTS}

We thank the participants for sharing their experiences and insights, and for their unending support of this project. We thank Jessica Krahn, Jane McCall, Anthony dePadua for their assistance in collecting data from the many sites across Canada. We are grateful for the insights and reflections from many co-investigators and collaborators e.g., from the Cana- 
dian Association of Nurses in AIDS Care, CATIE, and the many AIDS Services Organizations and health clinics across Canada who participated in the original and follow-up study. The Faculty of Nursing at the University of Alberta provided financial resources through the EFF grant to undertake this

\section{REFERENCES}

[1] Mill J, Edwards N, Jackson R, et al. Accessing health services while living with HIV: Intersections of stigma. Can J Nurs Res. 2009; 41(3): 168-85.

[2] Mill J, Caine V, Arneson C, et al. Past experiences, current realities and future possibilities for HIV nursing education and care in Canada. J Nurs Educ Pract. 2014; 4(5): 183-98.

[3] Baumgartner LM. Book review: Understanding and promoting transformative learning. 2nd Ed. by P. Cranton, San Francisco: JosseyBass 2006. Adult Educ Quart. 2007; 57(3): 4-266.

[4] Grossman S. Mentoring in nursing: a dynamic and collaborative process. New York: Springer Pub. Co.; 2013.

[5] Woolnough HM, Fielden SL. Mentoring in nursing and healthcare. Supporting career and personal development. Chichester, West Sussex: John Wiley \& Sons, Ltd.; 2017.

[6] Caine V, Mill J. Essentials of Community-based Research. San Francisco: Left Coast Press; 2017.

[7] Hacker K, Tendulkar SA, Rideout C, et al. Community capacity building and sustainability: Outcomes of community-based participatory research. Prog Community Health Partnersh . 2012; 6(3): 349-60. PMid:22982848 https ://doi.org/10.1353/cpr.2012.0048

[8] Israel BA, Coombe CM, Cheezum RR, et al. Community-based participatory research: A capacity-building approach for policy advocacy aimed at eliminating health disparities. Am J Public Health. 2010; 100(11): 2094-102. PMid:20864728 https : //doi.org/10 .2105/A JPH. 2009.170506

[9] Flicker S, Savan B, Kolenda B, et al. A snapshot of community-based research in Canada: Who? What? Why? How? Great Britain: Oxford University Press; 2008. 106 p

[10] Beckman M, Long JF. Community-based research: teaching for community impact. First edition. Sterling, Virginia: Stylish Publishing LLC. 2016. study. The original mentorship project was funded through Canadian Institutes of Health Research (CIHR). Vera Caine holds a CIHR New Investigator Award.

\section{Conflicts of InTEREST Disclosure}

The authors declare that there is no conflict of interest.
[11] Beckman M, Penney N, Cockburn B. Maximizing the impact of community-based research. J. Higher Educ Outreach Engage. 2011; 15(2): 83-103.

[12] Caine V, Mill J, O'Brien K, et al. Implementation process of a Canadian community-based nurse mentorship intervention in HIV care. J Assoc Nurses AIDS Care. 2016 May; 27(3): 274-84.

[13] Worthington CA, O'Brien KK, Mill J, et al. A mixed-methods outcome evaluation of a mentorship intervention for Canadian nurses in HIV care. J Assoc Nurses AIDS Care. 2016 Sep; 27(5): 677-97.

[14] Ontario AIDS Network: The Ontario Accord [Internet]. Ontario. Ontario AIDS Network, c2018 [cited 2018 Apr 23]. Available from: http://oan.red/ontario-accord/

[15] Wyles E, McLeod H, Goodfellow G. A novel approach to bridge the gap between didactic and clinical education. Optometric Educ. 2013; 39(1): 12-9.

[16] World Health Organization An approach to rapid scale-up: Using HIV/AIDS treatment and care as an example. HIV/AIDS, Tuberculosis and Malaria Evidence and Information for Policy. 2004. Available from: http://www.who.int/hiv/pub/prev_care/en /rapidscale_up.pdf

[17] Riessman CK. Narrative methods for the human sciences. Los Angeles: Sage Publications. 2008.

[18] NVivo qualitative data analysis Software; QSR International Pty Ltd. Version 11, 2012.

[19] Morse JM. Emerging From the Data: The Cognitive Processes of Analysis in Qualitative Inquiry. In:Thousand Oaks, California; Sage Publications, Inc; 1994; 23 p.

[20] UNAIDS. From principle to practice: The Greater Involvement of People Living with or Affected by HIV/AIDS (GIPA). 1999. Available from: http://data.unaids.org/pub/briefingnote /2007/jc1299_policy_brief_gipa.pdf

[21] Phillips JC, Caine V, Dewart G, et al. Teaching HIV-specific content for pre-licensure nursing and health professions students: a review and synthesis. AIDS Care. 2018 Aug 16 [cited 2018 Sep 25]; 1-8. 